\title{
Adjunctive sublingual misoprostol for secondary prevention of post- partum hemorrhage during cesarean delivery: double blind placebo randomized controlled trial
}

\author{
Hany F. Sallam, Nahla W. Shady*
}

Department of Obstetrics and Gynecology, Faculty of Medicine, Aswan University, Egypt

Received: 13 November 2017

Accepted: 09 December 2017

*Correspondence:

Dr. Nahla W. Shady,

E-mail: nahlagyn@yahoo.com

Copyright: () the author(s), publisher and licensee Medip Academy. This is an open-access article distributed under the terms of the Creative Commons Attribution Non-Commercial License, which permits unrestricted non-commercial use, distribution, and reproduction in any medium, provided the original work is properly cited.

\begin{abstract}
Background: Cesarean delivery is the most frequently performed major operative procedure worldwide. Objective of present study was to evaluate randomized evidence regarding efficacy and safety of sublingual misoprostol for secondary prevention of post-partum hemorrhage during and after cesarean delivery in women receiving prophylactic oxytocin as primary preventive tools and bleed around $500 \mathrm{ml}$ by visual analogue estimation.

Methods: A prospective, randomized, double-blind, placebo-controlled trial was performed at an obstetrics and gynecology department Aswan university hospital, Egypt, between October 2015 and September 2017. Women were eligible if they were undergoing elective cesarean under spinal anesthesia and were bleed around 500ml by visual analogue estimation. All participants received 10 IU oxytocin after delivery of the newborn. Participants were randomly assigned (1:1) to receive $400 \mu \mathrm{g}$ misoprostol or matched placebo sublingually using a computer-generated random number sequence. Participants and providers were masked to assignment. The primary outcomes were intraoperative and postoperative blood loss.

Results: There was high significant reduction in intraoperative blood loss in misoprostol group (711.0 \pm 188.41$)$ compared with placebo group $(915.33 \pm 293.72)(\mathrm{P}=0.0001)$. The all estimated blood loss during CS and 24 hours postoperative was significant lower in misoprostol group $(890.39 \pm 194.49)$ than that in placebo group (1096.9 \pm 300.05$)$ $(\mathrm{p}=0.0001)$.

Conclusions: Misoprostol as an adjunct to oxytocin as secondary prevention of pot partum hemorrhage seemed to be more effectively reduce blood loss than did placebo with oxytocin alone.
\end{abstract}

Keywords: Cesarean delivery, Post-partum hemorrhage, Sublingual misoprostol

\section{INTRODUCTION}

Cesarean delivery is the most frequently performed major operative procedure worldwide. Compared with women delivering vaginally, women undergoing cesarean have an increased risk of high blood loss and so are more likely to need a blood transfusion. ${ }^{1}$ The global rise in the incidence of cesarean delivery in the past decade has possibly contributed to the increase rate of postpartum hemorrhage $(\mathrm{PPH})$ in high-income countries. ${ }^{2}$ The risk of $\mathrm{PPH}$ is further increased in the presence of risk factors such as multiple pregnancy, polyhydramnios, grand multiparity, severe pre-eclampsia, peripartum hemorrhage, prolonged and obstructed labor, augmented labor, obesity, and anemia. ${ }^{3}$

Postpartum hemorrhage is usually defined as the loss of more than $500 \mathrm{~mL}$ of blood after vaginal delivery and 
$1000 \mathrm{~mL}$ of blood after caesarean delivery. ${ }^{3}$ A leading cause of death in the developing world, accounting for $27 \%$ of maternal deaths. In well-resourced countries it is the most significant cause of maternal morbidity. ${ }^{3}$ Approximately $36 \%$ of all the lower segment CS deliveries are complicated by primary PPH. So estimated blood loss more than "average" or $500 \mathrm{~mL}$ should alert the obstetrician to possible excessive bleeding. ${ }^{4}$

A reduction of operative blood loss at cesarean section has a great benefit to the patients in terms of decreased postoperative morbidity and a decrease in risks associated with blood transfusions. ${ }^{4}$

Oxytocin, the gold standard oxytocic agent, is widely used during cesarean delivery to prevent $\mathrm{PPH}$, even though some studies have raised concerns about its efficacy and adverse effects., ${ }^{5,6}$ Misoprostol has been evaluated as an alternative to oxytocin during cesarean delivery, and has also been used in combination with oxytocin. ${ }^{7-17}$ Two meta-analyses concluded that misoprostol was as effective as oxytocin and that the combination of the misoprostol and oxytocin is better than is oxytocin alone for the prevention of PPH. However, women with known risk factors for $\mathrm{PPH}$, who are expected to benefit from an additional oxytocic agent, were excluded from some of the studies. ${ }^{12-14,16,17}$ Thus, the existing evidence on the optimal uterotonic agent during cesarean for high-risk women is insufficient.

Universal prophylaxis (primary prevention) lowers mean postpartum blood loss, which reduces the incidence of postpartum hemorrhage (PPH). However, administration of prophylactic uterotonics during cesarean section does not eliminate the need for treatment for some women. ${ }^{18}$

Improving obstetric care for the management of PPH remains difficult, although greatly needed. Reports from confidential enquiries into maternal deaths show that most deaths due to PPH involve delayed and substandard care in the diagnosis and management of hemorrhage. ${ }^{19}$

Misoprostol has a role in the management of uterine atony. Because of its wide variety of clinical applications, misoprostol is an active topic of research. Questions remain about the optimal dose and route, and whether prophylactic use should be limited to situations in which active management of the third stage of labor (oxytocin) is not possible. But its ease of administration, modest side-effect profile, lack of contraindications, and proven efficacy make it a useful option. ${ }^{20}$

WHO maintained that there was still uncertainty about the lowest effective dose and optimal administration route of misoprostol for prevention of post-partum haemorrhage. ${ }^{21}$ However, adequate evidence is lacking to assess the effectiveness of misoprostol as adjunctive to oxytocin for preventing PPH, including the considerations about their doses and administration route and time. This study aims to examine randomized evidence regarding comparative efficacy and safety of sublingual misoprostol for secondary prevention of postpartum hemorrhage during and after cesarean delivery in women receiving prophylactic oxytocin as primary preventive tools and bleed more than $500 \mathrm{ml}$ by visual analogue estimation.

\section{METHODS}

This study was a double blinded randomized controlled study conducted after local ethical committee agreement at Aswan University Hospitals from October 2015 to September 2017. Study inclusion Criteria were women who undergone elective cesarean section (C.S) and exposed to intraoperative bleeding about $500 \mathrm{ml}$ diagnosed by visual analogue estimation due to atonic uterus. (Twin -grand multipara - macrosomia -breechrepeated previous caesarian delivery) were the indication of CS in our study. Women with medical disorder, placenta previa, placenta accrete, allergy to misoprostol and intraoperative bleeding due to causes other than uterine atony were excluded from the study.

\section{Eligible participants}

There were 980 pregnant women at term (37:40 weeks) gestation scheduled for elective low segment cesarean delivery under spinal anesthesia were invited for this study. 220 not meeting inclusion criteria and fifty refused to participate. 710 women undergone elective cesarean section, 530 women were excluded as they did not reach to $500 \mathrm{ml}$ intraoperative bleeding and 180 women who reach about $500 \mathrm{ml}$ intraoperative bleeding were included and continued the study. All participants undergone detailed history, general, abdominal and ultrasound examination. The participants who fulfilled the eligibility criteria were explained about the study with the beneficial and possible adverse effects of misoprostol. Informed consent was obtained from them.

\section{Randomization}

Patients were randomized into two groups, each compromised of ninety patients according to a twoblocked randomization list which was coded ( 1 or 2 ) at 1:1 ratio. The two parallel groups were prepared using a Computer-generated randomization system. The allocated groups will be concealed in serially numbered sealed opaque envelopes that will only be opened after recruitment. Patient allocation will be performed during CS by an independent person, who will not otherwise be involved in this study. The trial will be appropriately blinded; the participants, outcome assessors and the surgeon performing the procedure will be blinded to the medication type, which will be used.

\section{Intervention}

All women preformed CS by using spinal anesthesia, pfannenstiel incision of the skin, open of abdomen in 
layers, lower uterine segment transverse incision. After delivery of the baby $10 \mathrm{IU}$ of oxytocin intravenous infusion administered by the anesthesiologist then delivery of the and placenta, during $\mathrm{CS}$, intraoperative bleeding was estimated, if bleeding around $500 \mathrm{ml}$ and due to atonic uterus then $400 \mu \mathrm{g}$ of sublingual misoprostol (misotac) or placebo in form of ranitidine (ranitak) were administered. After that the blood loss was calculated to the end of the operation and 24 hours postoperative.

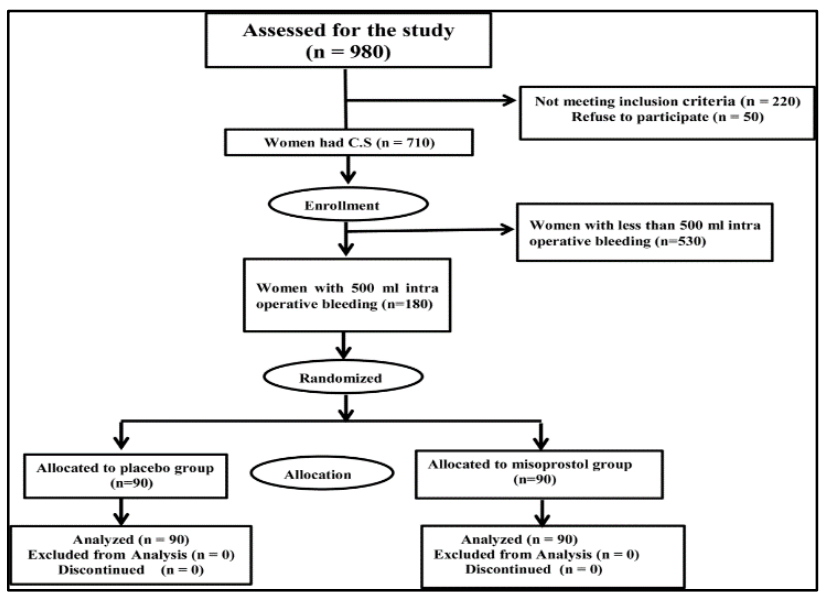

Figure 1: Flowchart of the study.

\section{Blood loss estimation}

Intraoperative blood loss was measured by adding the volume of the contents of the suction bottle which was changed after delivery of placenta to avoid being mixed with amniotic fluid and blood from parities and the difference in weight (in grams) between the dry and the soaked operation sheets and towels (1 gram = $1 \mathrm{ml}$.). Post-operative blood loss was measured by calculate the difference in weight (in grams) between the dry and the soaked pads $(1$ gram $=1 \mathrm{ml})$. After that the total blood loss was calculated by the addition of intraoperative and postoperative blood loss.

\section{Study outcome}

The primary outcome was estimation of intraoperative, postoperative and total blood loss ( $\mathrm{ml})$.

The secondary outcome measures included need for blood transfusion, other surgical interventions, additional uterotonics and operative time. Also, Hemoglobin concentration was done in all patients preoperative and 24 hours postoperative and the change in concentration was noted. Any side effects such as fever, shivering, unpleasant taste, nausea, vomiting and diarrhea were recorded.

\section{Statistical analysis}

Data were entered and statistically analyzed using the Statistical Package for Social Sciences (SPSS) version 16. Qualitative data were described as numbers and percentages. Chi-square test was used for comparison between groups. Quantitative data were described as means (SD) or medians, as appropriate. They were tested for normality by Kolmogorov-Smirnov test. In the normally distributed variables, independent sample t-test was used for comparison between groups. In the nonnormally distributed variables, Mann-Whitney test was used for comparison between groups. Odds ratios and their $95 \%$ confidence interval were calculated. "p value $\leq 0.05$ " was considered to be statistically significant.

\section{RESULTS}

Out of 980 eligible women delivered by CS. 180 women were consented to participate and continued the study. They were randomized to two groups; misoprostol group and placebo group.

Table 1: Demographic criteria of the study groups.

\begin{tabular}{|c|c|c|c|}
\hline Characteristics & Placebo group $(n=90)$ & Misoprostol group $(\mathrm{n}=90)$ & Significance \\
\hline Age (year) & $29.39 \pm 2.48$ & $29.48 \pm 2.71$ & 0.819 \\
\hline Weight $(\mathrm{Kg})$ & $78.32 \pm 6.16$ & $78.33 \pm 6.16$ & 0.990 \\
\hline Gestational age (week) & $38.31 \pm 0.87$ & $38.31 \pm 0.84$ & 1.00 \\
\hline Parity & $3(1-8)$ & $3(1-9)$ & 0.901 \\
\hline No. of CS & $2(0-5)$ & $2(0-5)$ & 0.807 \\
\hline \multicolumn{4}{|l|}{ Indication of CS } \\
\hline Twin & $10(11.1)$ & $11(12.2)$ & \\
\hline Breech & $15(16.7)$ & $14(15.6)$ & 0.967 \\
\hline Macrosomia & $15(16.7)$ & $13(14.4)$ & \\
\hline Repeated CS & $50(55.6)$ & $52(57.8)$ & \\
\hline Initial Hemoglobin & $10.62 \pm 0.73$ & $10.63 \pm 0.77$ & 0.961 \\
\hline
\end{tabular}

C.S (cesarean section). \#Variables are presented as mean \pm standard deviation, median (minimum-maximum) and number (percentage). 
There was no significant difference between the two groups with respect to their age, weight, gestational age, parity, number of CS, indication of $\mathrm{CS}$ and initial hemoglobin (Table 1). There was high significant reduction in intraoperative blood loss in misoprostol group $(711.0 \pm 188.41)$ compared with placebo group (915.33 \pm 293.72$) \quad(\mathrm{P}=0.0001)$. However, there was no significant difference in post-operative bleeding between the two groups. $(\mathrm{p}=0.831)$.

The all estimated blood loss during CS and 24 hours postoperative was significant lower in misoprostol group $(890.39 \pm 194.49)$ than that in placebo group $(1096.9 \pm 300.05)(\mathrm{p}=0.0001)$ (Table 2).

Table 2: Primary outcome of the study groups.

\begin{tabular}{|llll|}
\hline Variables & Placebo group $(\mathbf{n}=90)$ & Misoprostol group $(\mathbf{n}=90)$ & Significance \\
\hline Intra-operative blood loss $(\mathrm{ml})$ & $915.33 \pm 293.72$ & $711.0 \pm 188.41$ & $0.0001^{*}$ \\
\hline Post-operative blood loss $(\mathrm{ml})$ & $181.56 \pm 34.26$ & $180.5 \pm 31.98$ & 0.831 \\
\hline All blood loss $(\mathrm{ml})$ & $1096.9 \pm 300.05$ & $890.39 \pm 194.49$ & $0.0001^{*}$ \\
\hline
\end{tabular}

*Statistically significant, \#Variables are presented as mean \pm standard deviation

The incidence of blood transfusion was increased in placebo group $50(55.6 \%)$ women compared with 18 $(20.0 \%)$ women in misoprostol group, $(\mathrm{P}=0.0001)$. More women in placebo group $(66.7 \%)$ than in misoprostol group $(26.7 \%)$ required additional uterotonics $(\mathrm{p}=0.0001)$. Also, more women in placebo group (36.7\%)than in misoprostol group $(10.0 \%)$ required more surgical intervention $(\mathrm{p}=0.0001)$. There was a highly significant reduction in operative time in misoprostol group (70.29 \pm 15.52$)$ compared with placebo group $(98.1 \pm 9.85) \quad(\mathrm{P}=0.0001)$. There was no significant difference in related to 24-hour post-operative hemoglobin concentration between the two groups. $(\mathrm{p}=0.245)$ (Table 3).

Table 3: Secondary outcome of the study groups.

\begin{tabular}{|llll|}
\hline Variables & Placebo group $(\mathrm{n=90})$ & Misoprostol Group $(\mathrm{n}=90)$ & Significance \\
\hline Blood transfusion & $50(55.6)$ & $18(20.0)$ & $0.0001^{*}$ \\
\hline Additional Uterotonics & $60(66.7)$ & $24(26.7)$ & $0.0001^{*}$ \\
\hline Extra surgical intervention & $33(36.7)$ & $9(10.0)$ & $0.0001^{*}$ \\
\hline Operative time & $98.1 \pm 9.85$ & $70.29 \pm 15.52$ & $0.0001^{*}$ \\
\hline Post-operative hemoglobin & $9.72 \pm 0.66$ & $9.84 \pm 0.73$ & 0.245 \\
\hline
\end{tabular}

*Statistically significant, \#Variables are presented as number (percentage) and mean \pm standard deviation.

Table 4: Side effect of the study groups.

\begin{tabular}{|llll|}
\hline Side effect & Placebo group $(\mathbf{n = 9 0})$ & Misoprostol Group $(\mathbf{n}=90)$ & Significance \\
\hline Fever & $11(12.2)$ & $37(41.1)$ & $0.0001^{*}$ \\
\hline Shivering & $13(14.4)$ & $34(37.8)$ & $0.0001^{*}$ \\
\hline Nausea & $13(14.4)$ & $15(16.7)$ & 0.681 \\
\hline Vomiting & $7(7.8)$ & $9(10.0)$ & 0.600 \\
\hline Diarrhea & $3(3.3)$ & $8(8.9)$ & 0.120 \\
\hline Unpleasant taste & $2(2.2)$ & $13(14.4)$ & $0.003^{*}$ \\
\hline
\end{tabular}

*Statistically significant, \#Variables are presented as number (percentage).

About the side effect, there was significant increase in incidence of fever (41.1\%), shivering (37.8\%) and unpleasant taste $(14.4 \%)$ in misoprostol group than placebo group [fever $(12.2 \%)$, shivering (14.4\%) and unpleasant taste $(2.25)](\mathrm{p}=0.0001,0.0001$ and 0.003 respectively) however there was no significant difference between the two groups in related to nausea, vomiting and diarrhea $(\mathrm{P}=0.681,0.600$ and 0.120 respectively) (Table 4).

\section{Study power calculation}

As the average amount of blood loss was the primary outcome of this research, study power was calculated online (www.dssresearch.com) using the average value of 
the placebo group $(1096.9 \pm 300.05)$ and that of the misoprostol group $(890.4 \pm 194.9)$, the sample size was 90 for each group with $95 \%$ confidence level. The study power was found to be $100 \%$.

\section{DISCUSSION}

The long life outside the refrigerator and oral administration of misoprostol make it attractive for use in in prevention and management of post-partum hemorrhage especially low-resource areas. It also has no effect on blood pressure or cause Broncho-constriction, and so can be safely used in women with asthma. ${ }^{21}$ As regard the use of misoprostol for PPH prophylaxis, it appears that it reduces postpartum blood loss, but that it is not as effective as oxytocin. Oxytocin is therefore now recommended over misoprostol as a first line for PPH prophylaxis. $^{21}$ Instead of sudden massive hemorrhage, postpartum bleeding is frequently steady. So that estimated blood loss is commonly only approximately half the actual loss. If atony persists, bleeding may appear to be only moderate at any given instant but may continue until serious hypovolemia develops. ${ }^{21}$

In present study we hypothesized that the adjunctive use of misoprostol for secondary prevention of post-partum hemorrhage may be beneficial after administration of oxytocin as primary preventive tool for prevention of post-partum hemorrhage during cesarean section when estimated blood loss more than "average" or $500 \mathrm{~mL}$.

At the best of our knowledge we are the first to address this issue with the main outcome of our results were that adjunctive use of sublingual misoprostol decreases number of cases with postpartum hemorrhage with decrease the main intraoperative and total blood loss during cesarean section where there was increase blood loss around $500 \mathrm{ml}$ by visual estimation of blood loss during cesarean section. There was high significant reduction in intraoperative blood loss in misoprostol group (711.0 \pm 188.41$)$ compared with placebo group $(915.33 \pm 293.72)(\mathrm{P}=0.0001)$. The all estimated blood loss during CS and 24 hours postoperative was significant lower in misoprostol group $(890.39 \pm 194.49)$ than that in placebo group $(1096.9 \pm 300.05)(\mathrm{p}=0.0001)$.

Widmer et al recruited 1400 women with PPH and compared the use of combined oxytocin and misoprostol $(600 \mu \mathrm{g})$ with the use of oxytocin alone. ${ }^{22}$ The results show no difference between groups in additional loss of $500 \mathrm{ml}$ (risk ratio, RR 1.01; 95\% confidence interval, 95\% CI $0.78-1.30$ ) or $1000 \mathrm{ml}$ (RR 0.76 ; 95\% CI 0.43 1.34). The conclusion is that in settings where oxytocin is available for the treatment of $\mathrm{PPH}$, there is no role for additional misoprostol. ${ }^{22}$

Two studies compared the efficacy of misoprostol and oxytocin as first-line treatments for PPH. The studies recruited a total of 40000 women from a range of units throughout the world, some of which routinely gave oxytocin for prophylaxis, and some that gave no prophylaxis. ${ }^{23,24}$ The women who developed PPH were randomized to receive a high-dose oxytocin infusion (40 iu over 15 minutes) or misoprostol (800 $\mu \mathrm{g}$, sublingually), each with placebos so as to ensure double blinding. In the units where there was no oxytocin prophylaxis there was less additional blood loss in those given oxytocins than for those given misoprostol. The difference was statistically significant for an extra loss of $300 \mathrm{ml}$ (RR 1.78; 95\% CI 1.40-2.26), but not for a loss of over $1000 \mathrm{ml}$ (RR 1.67; 95\% CI 0.40-6.96). In the units where women were given routine oxytocin prophylaxis, there was no difference in additional blood loss of $300 \mathrm{ml}$ (RR 1.12; 95\% CI 0.92-1.37), but more women in the misoprostol group had an additional loss of over $1000 \mathrm{ml}$ (RR 3.61; 95\% CI 1.02-12.85).

Compared with other routes of administration, sublingual and oral misoprostol have the shortest time to reach peak concentration (26-28 minutes, with a median time of 20 minutes), which is approximately one-third of the time of the vaginal route. Sublingual misoprostol also has the highest peak concentration and greatest bioavailability: $400 \mu \mathrm{g}$ administered sublingually approaches nearly twice the peak concentration of oral administration, and reaches between three and four times the concentration measured after vaginal administration. ${ }^{25}$ The avoidance of first-pass metabolism via the liver achieves a higher peak concentration by sublingual administration than by oral administration. This characteristic makes sublingual misoprostol more suitable than other routes of administration for clinical applications requiring a rapid onset of action, such as that required for the prevention of $\mathrm{PPH}^{25}$

Two systematic reviews, which includes the 2014 Cochrane review, focused on misoprostol to treat PPH and examined the optimal route and dosage, and its efficacy. ${ }^{20,26}$ Compared with 40 IU oxytocin infusion, 800 micrograms sublingual misoprostol was associated with a significant increase in the number of women who had blood loss of at least $1000 \mathrm{ml}$ (RR 2.65, 95\% CI 1.046.75 ) and who required blood transfusion (RR 1.47, 95\% CI 1.02-2.14). The authors concluded that oxytocin infusion should be recommended as first-line treatment for primary PPH. When used following prophylactic uterotonics, misoprostol and oxytocin infusion work similarly.

Lokugamage $\mathrm{AU}$ et al, conduct randomized single blinded two-center study, in South Africa. Sixty-four women with primary post-partum hemorrhage due to an atonic uterus were recruited. The primary outcome measure was whether the hemorrhage ceased within 20 minutes of administering the first line treatment, once hemorrhage was clinically recognized. There was a $28.1 \%$ difference between the misoprostol arm and the Syntometrine and Syntocinon arm $(\mathrm{p}=0.01)$. The authors concluded that misoprostol appears to be better than 
Syntometrine with a Syntocinon infusion at treating postpartum hemorrhage when caused by uterine atony. ${ }^{27}$

Othman ER et al conducted a randomized clinical trial on 120 pregnant women at term (37-40 weeks) gestation scheduled for elective cesarean delivery, who were assigned to either sublingual misoprostol $400 \mu \mathrm{g}$ or intravenous infusion of 20 units of oxytocin after delivery of the neonate. The overall mean blood loss was significantly lower in the misoprostol group compared to the oxytocin group $(490.75 \pm 159.90 \mathrm{~mL}$ vs. $601.08 \pm 299.49 \mathrm{~mL} ; \mathrm{p}=0.025)$. However, changes in hematocrit level (pre- and postpartum) was comparable between both groups. There was a need for additional oxytocic therapy in $16.7 \%$ and $23.3 \%$ after use of misoprostol and oxytocin, respectively $(p=0.361)$. Incidence of side effects such as shivering and metallic taste were significantly higher in the misoprostol group compared to the oxytocin group $(\mathrm{p}<0.001) .^{28}$

Two studies have combined misoprostol and oxytocin for the prevention of PPH at CS. ${ }^{30,31}$ The first one studied the effect of adding $200 \mu \mathrm{g}$ of sublingual misoprostol after delivery of the fetus to 20 IU of oxytocin given routinely to all cases and reported that the addition of misoprostol was effective in reducing blood loss. ${ }^{29}$ The second study enrolled a small sample $(n=56)$ of women undergoing emergency $\mathrm{CS}$ who received $5 \mathrm{IU}$ of intravenous oxytocin after cord clamping and were randomized to further receive either misoprostol orally or oxytocin infusion intravenously, no difference in blood loss was noticed between the two groups, although there was no control group included to assess whether either intervention had any added value. ${ }^{30}$

Singh showed that sublingual misoprostol at doses of both 400 and $600 \mu \mathrm{g}$ was more effective compared to either $5 \mathrm{IU}$ of intravenous oxytocin or $200 \mu \mathrm{g}$ of intravenous methylergometrine in decreasing blood loss during the third and fourth stages of labor. ${ }^{31}$

Chaudhuri et al conduct a randomized controlled study demonstrated that $400 \mu \mathrm{g}$ of sublingual misoprostol was a safe and effective therapeutic alternative to $10 \mathrm{IU}$ of intramuscular oxytocin in the routine management of third stage labor for prevention of PPH among low-risk women. ${ }^{32}$

In present study as regard the side effect, there was significant increase in incidence of fever $(41.1 \%)$, shivering $(37.8 \%)$ and unpleasant taste $(14.4 \%)$ in misoprostol group than placebo group [fever (12.2\%), shivering (14.4\%) and unpleasant taste (2.25).] ( $p=0.0001,0.0001$ and 0.003 respectively), this results in agreement with results from the different study. ${ }^{7-9,14,22,28}$

One limitation of present study was we did not use alkaline hematin method which is a validated method for accurate measurement of blood loss, but we used in state a gravimetric method to measure the amount of blood loss. ${ }^{33}$

Marcel $\mathrm{H}$ et al in veterinary surgery compare gravimetric and colorimetric methods of quantifying surgical blood loss and conclude that Estimation of blood loss using a gravimetric method is accurate and objective tool to evaluate intraoperative blood loss. ${ }^{34}$

One of the strength of present study was that double blind randomized study provides the evidence that Misoprostol as an adjunct to oxytocin as secondary prevention of pot partum hemorrhage may seemed to more effectively reduce blood loss than did placebo with oxytocin alone. Another strength of our study as the average amount of blood loss was the primary outcome of this research, study power was calculated online was found to be $100 \%$.

\section{CONCLUSION}

A single dose of $400 \mu \mathrm{g}$ sublingual misoprostol as an adjunct to oxytocin as secondary prevention of postpartum hemorrhage may be more effectively reduce blood loss than did placebo with oxytocin alone. Investigation of misoprostol use in larger population groups and with different dosages and another route together with comparison of other methods used to reduce bleeding cesarean section, is required.

Funding: No funding sources

Conflict of interest: None declared

Ethical approval: The study was approved by the Institutional Ethics Committee

\section{REFERENCES}

1. Tessier V, Pierre F, National College of Gynecologists and Obstetricians French, and National Agency of Accreditation and Evaluation in Health. Risk factors of postpartum hemorrhage during labor and clinical and pharmacological prevention. J Gynecol Obstet Biol Reprod (Paris) 2004 Dec;33(8 Suppl):4S29-56.

2. Joseph KS, Rouleau J, Kramer MS, Young DC, Liston RM, Baskett TF et al. Investigation of an increase in postpartum haemorrhage in Canada. BJOG. 2007;114:751-9.

3. Carroli G, Cuesta C, Abalos E, Gulmezoglu AM. Epidemiology of postpartum haemorrhage: a systematic review. Best Pract Res Clin Obstet Gynaecol. 2008;22(6):999-1012.

4. Thomas J, Callwood A, Paranjothy S. National Sentinel Caesarean Section Audit: update. Pract Midwife. 2000;3(11):20.

5. Munn MB, Owen J, Vincent R, Wakefield $M$, Chestnut DH, Hauth JC. Comparison of two oxytocin regimens to prevent uterine atony at cesarean delivery: a randomized controlled trial. Obstet Gynecol. 2001;98:386-90. 
6. Thomas JS, Koh SH, Cooper GM. Haemodynamic effects of oxytocin given as i.v. bolus or infusion on women undergoing Caesarean section. $\mathrm{Br} \mathrm{J}$ Anaesthiol. 2007;98:116-9.

7. Vimala N, Mittal S, Kumar S. Sublingual misoprostol versus oxytocin infusion to reduce blood loss at cesarean section. Int J Gynecol Obstet. 2006;92:106-10.

8. Eftekhari N, Doroodian M, Lashkarizadeh R. The effect of sublingual misoprostol versus intravenous oxytocin in reducing bleeding after caesarean section. J Obstet Gynaecol. 2009;29:633-6.

9. Chaudhuri P, Banerjee GB, Mandal A. Rectally administered misoprostol versus intravenous oxytocin infusion during cesarean delivery to reduce intraoperative and postoperative blood loss. Int $\mathrm{J}$ Gynecol Obstet. 2010;109:25-9.

10. Owonikoko KM, Arowojolu AO, Okunlola MA. Effect of sublingual misoprostol versus intravenous oxytocin on reducing blood loss at cesarean section in Nigeria: a randomized controlled trial. Obstet Gynaecol Res. 2011;37:715-21.

11. Hamm J, Russell Z, Botha T, Carlan SJ, Richichi K. Buccal misoprostol to prevent hemorrhage at cesarean delivery: a randomized study. Am J Obstet Gynecol. 2005;192:1404-6.

12. Fekih M, Jnifene A, Fathallah K, Ben Regaya L, Memmi A, Bouguizene $S$, et al. Benefit of misoprostol for prevention of postpartum hemorrhage in cesarean section: a randomized controlled trial. J Gynecol Obstet Biol Reprod (Paris). 2009;38:588-93.

13. Quiroga Díaz R, Cantú Mata R, Tello Gutiérrez HE, Puente Villalobos M, Montemayor Garza R, Martínez Mendoza A. Intrauterine misoprostol for the prevention of bleeding cesarean. Ginecol Obstet Mex. 2009;77:469-74.

14. Chalermpolprapa MD. Efficacy of sublingual misoprostol in prevention of postpartum hemorrhage in cesarean section: a randomized double-blinded, placebo-controlled trial. Med J. 2010;29:325-35.

15. Sood AK, Singh S. Sublingual misoprostol to reduce blood loss at cesarean delivery. J Obstet Gynaecol India. 2012;62:162-7.

16. Elsedeek MS. Impact of preoperative rectal misoprostol on blood loss during and after elective cesarean delivery. Int $\mathrm{J}$ Gynecol Obstet. 2012;118:149-52.

17. El Tahan MR, Warda OM, Rashad A, Yasseen AM, Ramzy EA, Ahmady MS, et al. Effects of preoperative sublingual misoprostol on uterine tone during isoflurane anesthesia for cesarean section. Rev Bras Anestesiol. 2012;62:625-35.

18. Su LL, Chong YS, Samuel M. Oxytocin agonists for preventing postpartum haemorrhage. Cochrane Database Syst Rev. 2007;(3):CD005457.

19. Lewis G. Saving mother's lives: reviewing maternal deaths to make motherhood safer-2003-2005. The seventh report of the Confidential Enquiries into maternal deaths in the United Kingdom. London: CEMACH;2007.

20. Mousa HA, Blum J, Abou El Senoun G, Shakur H, Alfirevic Z. Treatment for primary postpartum haemorrhage. Cochrane Database Syst Rev. 2014;(2):CD003249.

21. WHO Guidelines Approved by the Guidelines Review Committee. Who Recommendations for the Prevention and Treatment of Postpartum Haemorrhage. Geneva: World Health Organization;2012.

22. Widmer M, Blum J, Hofmeyr GJ, Carroli G, AbdelAleem H, Lumbiganon P, et al. Misoprostol as an adjunct to standard uterotonics for treatment of postpartum haemorrhage: a multicentre, double-blind randomised trial. Lancet. 2010;375:1808-13.

23. Blum J, Winikoff B, Raghavan S, Dabash R, Ramadan MC, Dilbaz B, et al. Treatment of postpartum hemorrhage with sublingual misoprostol versus oxytocin: results from a double-blind placebocontrolled randomized non-inferiority trial among women receiving prophylactic oxytocin. Lancet. 2010;375:217-23.

24. Winikoff B, Dabash R, Durocher J, Darwish E, Ngoc NTN, León $\mathrm{W}$ et al. Treatment of postpartum hemorrhage with sublingual misoprostol versus oxytocin: results from a double-blind, placebocontrolled, randomized, non-inferiority trial among women not exposed to oxytocin during labor. Lancet. 2010;375:210-6.

25. Tang OS, Schweer H, Seyberth HW. Pharmacokinetics of different routes of administration of misoprostol. Hum Reprod. 2002; 17:332-6.

26. Hofmeyr GJ, Walraven G, Gülmezoglu AM, Maholwana B, Alfirevic Z, Villar J. Misoprostol to treat postpartum haemorrhage: a systematic review. BJOG. 2005;112:547-53.

27. Lokugamage AU, Sullivan KR, Niculescu I, Tigere $\mathrm{P}$, Onyangunga F, Refaey HE, et al. A randomized study comparing rectally administered misoprostol versus syntometrine combined with an oxytocin infusion for the cessation of primary post partum hemorrhage. Acta Obstet Gynecol Scand. 2001;80:835-9.

28. Othman ER, Fayez MR, Abd El Aal DEM, Mohamed HSE, Abbas AM, Ali MK. Sublingual misoprostol versus intravenous oxytocin in reducing bleeding during and after cesarean section: a randomized clinical trial. Taiwan J Obstet Gynecol. 2016;55:791-5.

29. Fekih M, Jnifene A, Fathallah K, Ben Regaya L, Memmi A, Bouguizene $S$ et al. Benefit of misoprostol for prevention of postpartum hemorrhage in cesarean section: a randomized controlled trial. J Gynecol Obstet Biol Reprod (Paris). 2009;38(7):588-93.

30. Lapaire O, Schneider MC, Stotz M, Surbek DV, Holzgreve W, Hoesli IM. Oral misoprostol vs intravenous oxytocin in reducing blood loss after 
emergency cesarean delivery. Int J Gynecol Obstet. 2006;95(1):2-7.

31. Singh G, Radhakrishnan G, Guleria K. Comparison of sublingual misoprostol, intravenous oxytocin, and intravenous methylergometrine in active management of the third stage of labor. Int $\mathrm{J}$ Gynaecol Obstet. 2009;107(2):130-4.

32. Chaudhuri P, Biswas J, Mandal A. Sublingual misoprostol versus intramuscular oxytocin for prevention of postpartum hemorrhage in low-risk women. Int J Gynaecol Obstet. 2012;116(2):138142.

33. Larsson C, Saltvedt S, Wiklund I, Pahlen S, Andolf E. Estimation of blood loss after caesarean section and vaginal delivery has low validity with a tendency to exaggeration. Acta Obstet Gynecol Scand. 2006;85:1448-52.

34. Lee MH, Ingvertsen BT, Kirpensteijn J, Jensen AL, Kristensen AT. Quantification of surgical blood loss. Vet Surg. 2006;35(4):388-93.

Cite this article as: Sallam HF, Shady NW. Adjunctive sublingual misoprostol for secondary prevention of post-partum hemorrhage during cesarean delivery: double blind placebo randomized controlled trial. Int J Reprod Contracept Obstet Gynecol 2018;7:495-502. 